\title{
Human Hips, Breasts and Buttocks: Is Fat Deceptive?
}

\author{
Bobbi S. Low, R. D. Alexander, K. M. Noonan
}

School of Natural Resources, University of Michigan (B.S.L) and the

Museum of Zoology, University of Michigan (R.D.A.; K.M.N.), Ann

Arbor, Michigan

In humans, reproductive-age females, unlike other ages and classes of individuals, deposit fat preferentially on the breasts, hips, and buttocks. This suggests that such fat deposition is a deceptive sexual signal, mimicking other signals of high reproductive value and potential.

KEY WORDS: Deception; Sexual selection; Fat deposition.

$\mathbf{W}$

hen males invest parentally, as in humans, males as well as females are likely to exercise some choice (Darwin 1871; Trivers 1972). The traits males use are expected to be those which reflect the female's reproductive value (future lifetime expected reproduction; Fisher 1958; Williams 1966a,b) and current reproductive status (e.g., fertile, pregnant; cf. Gallup 1982, 1986). We will term this combined criterion "reproductive probability."

Previously, we have argued (Alexander 1971; Low 1979a) that breasts, hips, and buttocks as sexual signals cvolved in the context of females competing for the attention and parental commitment of powerful, resourcecontrolling males. We hypothesized that (1) large breasts indicate to males the ability of a female to supply a large amount of high-quality milk uninterruptedly for a period of years and (2) broad hips reflect ability to carry a fetus and give birth with relative ease. We also suggested that when enlargement of hips and breasts result mainly from fat deposits the signal is deceptive (cf Barnett 1983, and Smith 1984).

There is little disagreement that fat provides efficient energy storage (e.g., Stini 1981), and the observation that human females tend to have greater fat storage than males has been suggested to result from the high-

Received March 29, 1985; revised December, 1986.

Address reprint requests to: Bobbi S. Low, Ph.D., School of Natural Resources, Samuel Trask Dana Building, The University of Michigan, Ann Arbor, MI 48109-1115. 
energy drain of pregnancy and lactation (Anderson 1983; Stini 1981; HussAsmore 1980; J. B. Lancaster 1984; J. B. and C. H. Lancaster 1977). Here we are concerned with dimorphism in the distribution of fat rather than the amount.

Cant (1981) and Huss-Ashmore (1980) argued that fat deposited in the breasts, hips, and buttocks of human females simply indicates nutritional reserves and a corresponding ability to provide much parental effort for a male's offspring. Cant further argued that fat in other locations might be Inaladaptive (e.g., ankles or wrists), suggestive of malnutrition (belly), or ambiguous (everywhere). Masia-Lees et al. (1986) argued that permanently enlarged breasts may simply be a by-product of selection for increased fat storage in a physiological environment of high estrogen levels. They argue that sexual selection need not be involved.

Gallup (1982) suggested that breast size and shape have evolved to indicate what he called "probability of ovulating," reflecting both age and nutritional status. Evidently Gallup meant this term in a way roughly equivalent to our term reproductive probability. Gallup suggested (1) that breast size is limited by effects of increased size on shape, and that (2) breast shapes associated with pregnancy, enlarged abdomens, menstrual flow, and old age signal anovulatory periods. These, he argued, are reasons why very large, drooping breasts and obesity may be unattractive. Gallup did not speak to the question of deception, nor did he discuss the significance of fat per se.

We agree with Cant that ". . . females possess ornaments whose signal meaning is directly related to factors bearing on reproductive success," and we regard Gallup's hypothesis as reasonable. We suggest, however, that it is explicitly reproductive probability that males assess, and the relationships among breast and hip size, nutrition, sexual sclection, and lactation deserve further discussion.

It seems to us that there are a limited number of alternative hypotheses about breast and hip structure and function in this context:

I. Some variations in breast, hip, and buttock size and shape are related to maternal fitness or reproductive value.

A. If fat is not deceptive, but rather a signal of the amount of energy a female has been able to store on the prevailing diet, its deposition should occur in sites that cannot be confused with mammary tissue or broad pelvises, so that its indication of nutritional status will be unequivocal. If fat deposition occurs on breasts and hips, it should be clearly discernible as fat, rather than an enhancement of specific attributes of breast and hips.

B. If fat is deceptive, mimicking other signals of high reproductive value, then:

1. If breast size correlates with the ability to produce and store milk, then males should prefer women with moderate-to-large breasts, particularly if the women are otherwise slender. If fat is deceptive, then, it should be deposited in ways that increase the apparent size of the breasts. 
2. If breast shape reflects information about reproductive value and reproductive state, males will tend to prefer high, rounded breasts (of whatever size) with moderate to pale pigmentation of the nipples (e.g., breasts typical of nonpregnant young women). If fat is deceptive, it should contribute to some such condition.

3. If hip width correlates with ease of giving birth, then if fat is deceptive, it should be deposited disproportionately on the sides of hips, increasing their apparent width relative to waist size.

II. Variations in breast, hip, and buttock size and shape are not related to maternal fitness and reproductive value. If males do use these characteristics in sexual selection, then the situation is analogous to Darwin's (1871) description of female choice in runaway sexual selection, and it is difficult to make any general predictions about what sizes or shapes of breasts and hips will be favored.

\section{THE NUTRITIONAL RESERVE HYPOTHESIS}

In some localities and situations, evidence of ability to store fat on the normal diet is almost certainly beneficial to women in sexual selection. Fat reserves are most likely to have this kind of significance in societies dependent on scarce and unpredictable resources (Low 1979a,b). If steatopygia is a female sexual attractant among some African tribes, as has been argued (e.g., Darwin 1871(I), pp. 345-346), and if it has no other function, the suggestion would be supported that clear displays of abundant fat reserves are favored. We note that steatopygia results primarily from fat deposits on the buttocks rather than the sides of the hips; that is, according to our hypothesis (IB above) in a nondeceptive rather than potentially deceptive location.

If women deposit fat as nutritional reserves, and if such reserves contribute significantly to parental effort, then, like actual mammary glands and wide pelvises, these reserves are likely to be used in sexual selection. Fat reserves used in sexual selection, however, are subject to the following constraints: the location should be unambiguous, and should not confuse or counter other sexual signals (like breast size or pelvic width). The likelihood of confusion caused by fat laid down in the pelvic and breast areas (i.e., is it really fat, or evidence of larger mammary glands and a wider pelvis?) alone seems sufficient to refute Cant's suggestion that fat laid down in these areas is nondeceptive unequivocal evidence of stored nutrients.

\section{THE DECEPTION HYPOTHESIS}

If fat is deceptive, it will presumably be deposited on the breasts so as to enhance their appearance as milk-producing organs, and in the pelvic region so as to exaggerate the impression of pelvic width and probable ease of 
parturition. In our hypothesis (or Gallup's), fatty exaggerations of breast size or pelvic width beyond certain points, or certain kinds of exaggeration, lower a female's attractiveness to males because they reveal deception (cf Horvath 1981; Savin-Williams and Hreedman 1977; Wiggins et al. 1968; Wiggins and Wiggins 1969). If, on the other hand, fat is not deceptive, lowered attractiveness from fat deposits will only occur when the amount of fat is so great as to (1) detract from an appearance of high reproductive value or (2) be maladaptive outside the context of sexual selection.

If fat is deceptive, moreover, exaggerated breast and pelvic developments that actually suggest fat deposits (e.g., large breasts on a fat woman as opposed to a slender one, or lumpy hips), rather than mammary development or a particular skeletal structure, will be less interesting to males. If fat is not deceptive the reverse should be true. Emphasis on a small waist (as in decoration or clothing, for example) suggests that the woman is not fat, but may exaggerate the appearance of pelvic width; similarly, a small waist and slender arms and legs imply that large breasts are not fatty (Low 1979a). If there is an erotic effect from such contrasts, the hypothesis of nondeceptive nutritional reserves is cast into doubt. If fat is not deceptive, it is difficult to see how any of these several predictions could be justified.

If we are right, female attributes that tend to exaggerate indications of a wide pelvis, other than fat deposits in the pelvic region (such as the motion of hips during walking), will be of great interest to males. There is much anecdotal evidence that male interest, as well as female responses (practiced cffects in walking, special clothing), accord with this hypothesis.

Breasts and buttocks are not the only unambiguous locations for fat deposits. For example, the upper arm skinfold pinch is one of the most reliable and unambiguous predictors of body composition and fat storage (Satwanti et al. 1980a,b; Klatch and McArdle 1973). If unambiguous signaling of fat reserves were a principal function of fat distributions, then fat upper arms on young women should be at least as attractive sexually as fat elsewhere. Perhaps this is so, but we suspect not. Breast size is also positively correlated with fat content of the body (Klatch et al., 1980), but the possibility of confusion of signals remains. At least in technological societies, upper arms tend not to be as fat in younger as in older women (Flint et al. 1977). Even if this means simply that in these affluent societies older women are fatter, the question is raised: If signaling fat reserves is important, why don't men use unambiguous indicators of fat reserves, such as upper arms, as signals and why do young women not mimic this condition by having fat upper arms?

Breasts, hips, and buttocks are clearly not the only adaptive locations for fat storage. Moreover, only reproductive-age females concentrate fat on the breasts and pelvic regions. Children (Parizkova and Roth 1972), adult males (Wolff and Steggerda 1943; Sukker 1976), and postreproductive females (Flint et al. 1977) all lay fat down in patterns that primarily involve other regions of the body. 
Comparison of people in tropical regions who have long been relatively unclothed and others who are usually heavily clothed might indicate whether or not there have been evolutionary divergences in body shape involving (at least) the appearance of pelvic width, or its contrast with the waist. Eskimos, like other peoples of cold regions, have relatively little body fat (Elsner 1963; Hurlich and Steegmann 1979), but it is more evenly distributed over the body, perhaps as the most effective pattern for insulation. The result is that Eskimo women are relatively thick-waisted (Seltzer 1933; Jenness 1923). If this difference is real, and if it results from fat deposits in the waists of heavily clothed women as opposed to the kinds of signals we have been suggesting in relatively unclothed women, it would tend to support our hypothesis. Women whose body shapes are more frequently hidden would gain less from emphasizing hip width by narrowing their waists if any expense is involved in the latter. Moreover, if thick waists are owing to fat deposits, their presence in women who have long tended to be heavily clothed would indicate that hips and breasts are not the only adaptive locations for fat deposits.

Our hypothesis generates a question Cant's and Gallup's hypotheses do not: Why should deceptive fat deposits have evolved, rather than the evolution of greater extremes in the actual traits that are being mimicked by the fat deposits? The implication is that there are expenses associated with having wide pelvises and large mammary glands that are compensated for in sexual selection but are not otherwise beneficial to females. Reductions of tendencies to hourglass figures in women who have long been heavily attired would also suggest that this may be the case. Such extreme attributes could, for example, contribute to success in birth and child care-thus, serve the male's interests-but subtract from a woman's fitness in other regards. Fat in mammary glands might be less expensive calorically, or might have a less deleterious effect on longevity, than additional mammary tissue per se. If this is true, and if success in sexual selection means for a female the acquiring of a mate capable of delivering more resources relevant to child rearing, then there would evolve less expensive alternatives to mammary tissues that are less significant in child-rearing but effective in sexual selection.

To show that pelvis width is unrelated to a female's ability to bear children, one would have to show that females do not typically have difficulty in giving birth, or that there is no correlation with pelvic structure. Neither suggestion appears supportable. In fact, women with narrow pelvises are more likely to experience difficulty than others (e.g., Page et al. 1976; Llewellyn-Jones 1977; Donald 1979), although other factors can cause difficulties (Russell and Richards 1971). We suggest rather that pelvic width and ease of parturition have been constrained by selective compromises that are as yet not understood. Extremely wide pelvises might interfere with locomotion deleteriously, especially before establishment of a pair bond. Males may have gained by tending to favor wider pelvises in sexual selection than were 
beneficial to females; if so, deceptive exaggeration could have been beneficial to females.

Cant and Gallup both dismiss the argument that large breasts due to mammary tissue provide more milk, and that this is adaptive, by noting (Cant) that some well-nourished females with large breasts give more milk than their babies can consume and (Gallup) that maintenance of breast size outside lactation is owing largely to fat deposits. However, if fat deposits maintain breast size and shape outside lactation as indicators of reproductive probability, there is no reason to expect honesty, and nothing in the argument implies either the existence of nutritional reserves or that human breasts provide more milk than is needed.

The particular manner in which human parental investment has changed most from that in other primates has to do with the length of time that a baby is suckled and tended. To demonstrate that breast size is irrelevant to the success of babies, one would have to show that breast size is uncorrelated with ability to provide high-quality milk across the 2-5 years that babies were characteristically nursed prior to the use of cow's milk and other nutritional supplements, and under the nutritional conditions that prevailed then for mothers (Alexander 1971). Such correlations have not been shown. It is one thing for an American or European woman who has been wellnourished all her life, and is well-nourished while lactating, to provide more milk, of unmeasured quality, than a very young baby can use; it is quite another for a female who has grown up and lives while lactating in a nontechnological society, where food is often at a premium, to provide an excess of high-quality milk uninterruptedly for several years.

Suggestions of geographic or other variations in breast size raise the question of whether small breasts may be more typical in regions or cultures in which women are able to nurse their babies more frequently. Human breasts, like the mammary glands of other mammals, have two primary functions: to produce milk and to store it. Nonhuman mammals vary remarkably in the frequency of nursing (Ben Shaul 1962). In species like the red kangaroo and the brown bear, nursing is essentially continuous, in the former case with the offspring continuously attached during its early life. Here we may assume that the storage function is minimal. In other species, such as Virginia deer, nursing occurs at intervals as long as 12 hours, with the juvenile spending the rest of the time hidden and apart from the mother. Here the storage function has to be considerably more important than in similar species that nurse much more frequently, and the udder is therefore larger. Among domestic animals in which the juvenile stays with the mother there are often considerable differences in frequency of nursing and in udder size (Hafez 1975; Waring 1983).

Increases in size, and changes in shape, of the human breast, compared to other primates, and perhaps differences among women in different parts of the world, may, as in nonhumans, have to do with differences in the storage function. To test this hypothesis would seem to require an under- 
standing of long-term differences in practices of child-rearing. There is evidence that frequency of nursing varies considerably in human societies (e.g., Konner 1981; WHO 1981, 1982), but to our knowledge no systematic comparison exists, and data on length and frequency of nursing bouts are lacking.

In summary, we believe that the observations and arguments presented above (1) suggest that breasts and hip size and shape are important in sexual selection, and (2) support the hypothesis that fat that accumulates in the breasts and buttocks of reproductive-age human females may often represent deceptive signals about ability to provide milk and give birth easily. These conclusions are consistent with the more general argument that sexual traits in the human female have evolved in the context of obtaining resources from males, to be used principally or wholly in parental care (Alexander and Noonan 1979; Symons 1979; Strassmann 1981).

\section{REFERENCES}

Alexander, R.D. The search for an evolutionary philosophy of man. Proceedings of the Royal Society Victoria 84(1): 99-120, 1971.

Alexander, R.D., and Noonan, K.M. Concealment of ovulation, parental care, and human social evolution. In Evolutionary Biology and Human Social Behavior: an Anthropological Perspective, N. Chagnon and W. Irons (Eds.). North Scituate, MA: Duxbury, 1979 , pp. 436-453.

Anderson, Peter. The reproductive role of the human breast. Current Anthropology 24:25-45. Barnett, S.A. Humanity and natural selection. Ethology and Sociobiology 4: 35-51, 1983.

Ben Shaul, D.M. The composition of the milk of wild animals. International Zoo Yearbook 4: $333-342,1962$.

Cant, J.G.H. Hypothesis for the evolution of human breasts and buttocks. American Naturalist 117: 199-204, 1981.

Darwin, C.R. The Descent of Man, and Selection in Relation to Sex. London: Murray, 1871, 2 vols.

Donald, I. Practical Obstetrics Problems. London: Lloyd-Luke Medical Books, 1979.

Elsner, R.W. Skinfold thickness in primitive peoples native to cold climates. New York Academy of Science Annals 110: 503-514, 1963.

Fisher, R.A. The Genetical Theory of Natural Selection. New York: Dover, 1958.

Flint, M.M., Drinkwater, B.L., Wells, C.L., and Horvath, S.M. Validity of estimating body fat of females: Effect of age and fitness. Human Biology 49: 559-572, 1977.

Gallup, G.G. Permanent breast enlargement in human females: A sociobiological analysis. Journal of Human Evolution 11: 597-601, 1982.

Unique features of human sexuality in the context of human evolution. In Alternative Approaches to the Study of Sexual Behavior, D. Byrne and K. Kelley (Eds.). Hillsdale, NJ: Erlbaum, 1986, pp. 13-42.

Hafez, E.S.E. The Behavior of Domestic Animals, 3rd ed. Baltimore: Williams \& Wilkins, 1975.

Horvath, T. Physical attractiveness: the influence of selected torso parameters. Archives of Sexual Behavior 10(1): 21-24, 1981.

Hurlich, M.G., and Steegmann, A.T., Jr. Hand immersion in cold water at $5^{\circ} \mathrm{C}$ in sub-arctic Algonkian Indian males from two villages: A European admixture effect? Human Biology 51: 255-278, 1979.

Huss-Ashmore, R. Fat and fertility: Demographic implications of differential fat storage. Year book of Physical Anthropology 23: 65-91, 1980. 
Jenness, D. Physical Characteristics of the Copper Eskimos. Ottawa: F. A. Acland, Kings Printer, 1923.

Klatch, F.I., and McArdle, W.D. Prediction of body-density from simple anthropometric measurements in college men and women. Human Biology 45: 445-454, 1973.

Klatch, V.L., Campaigne, B., Freedson, P., Sady, S., Klatch, F.I., and Behnke, A.R. Contribution of breast volume and weight to body fat distribution in females. American Journal of Physical Anthropology 53: 93-100, 1980.

Konner, M.J. Evolution of human behavior development. In Handbook of Cross-Cultural Development, R.H. Monroe and B.B. Whiting (Eds.). New York: Garland, 1981, pp. 351 .

Lancaster, J.B. Evolutionary perspectives on sex differences in higher primates. In Gender and the Life Course, A.S. Rossi (Ed.). Hawthorn, NY: Aldine, 1984, pp. 3-27.

- and Lancaster, C.H. Parental investment: The hominid adaptation. In How Humans Adapt: A Biological, Social, and Ecological Determinants, D.J. Ortner (Ed.). New York: Garland, 1977, pp. 563-602.

Llewellyn-Jones, D. Fundamentals of Obstetrics and Gynecology. Vol. I: Obstetrics. London: Faber and Faber, 1977.

Low, B.S. Sexual selection and human ornamentation. In Evolutionary Biology and Human Social Behavior, N.A. Chagnon and W. Irons (Eds.). North Scituate, MA: Duxbury, 1979a, pp. $462-487$.

- Environmental uncertainty and the parental strategies of marsupials and placentals. American Naturalist 112: 197-213, $1979 \mathrm{~b}$.

Masia-Lees, F.E., Relethford, J.H., and Sorger, T. Evolutionary perspectives on permanent breast enlargement in human females. American Anthropologist 88: 423-429, 1986.

Page, E.W., Villee, C.A., and Villee, D.B. Human Reproduction: The Core Content of Obstetrics, Gynecology and Perinatal Medicine, 2nd ed. Philadelphia: Saunders, 1976.

Parizkova, J., and Roth, Z. The assessment of depot fat in children from skinfold thickness measurements by Holtain (Tanner/Whitehouse) Caliper. Human Biology 44(4): 613$620,1972$.

Russell, J.G.B. and Richards, B. A review of pelvimetry data. British Journal of Radiology 44: 780-784, 1971.

Satwanti, K.M., Singh, I.P., and Bharadwaj, H. Body fat from skinfold thickness and weightheight indices: A comparison. Zeitschrift fuer Morphologie und Anthropologie 71: 93100, 1980a.

— Singh, I.P., and Bharadwaj, H. Body fat and fat-free mass assessed by densite metric techniques in adult Indian women. Zeitschrift fuer Morphologie und Anthropologie 71: 274-284, $1980 \mathrm{~b}$.

Savin-Williams, R.C., and Freedman, D.G. Bio-social approach to human behavior. In Primates Bio-social Development: Biological, Social, and Ecological Determinants, S. Chevalier-Skolnikoff and F.E. Poirier (Eds.). New York: Garland, 1977, pp. 563-602.

Seltzer, C.C. The anthropometry of the Western and Copper Eskimo based on data of Viljalmur Stefansson. Human Biology 5: 313-370, 1933.

Smith, R.L. Human sperm competition. In Sperm Competition and the Evolution of Animal Mating Systems, R.L. Smith (Ed.). New York, Academic, 1984, pp. 601-659.

Stini, W.A. Body composition and nutrient reserves in evolutionary perspective. World Review Nutrition and Dietetics 37: 55-83, 1981.

Strassman, B. Sexual selection, paternal care and concealed ovulation in humans. Ethology and Sociobiology 2: 31-40, 1981.

Sukker, M.Y. Skinfold thickness and body fat in adult Fur men and women of Western Sudan. Human Biology 48: 315-321, 1976.

Symons, D. The Evolution of Human Sexuality. Oxford: Oxford University Press, 1979.

Trivers, R.L. Parental investment and sexual selection. In Sexual Selection and the Descentof Man: 1871-1971, B. Campbell (Ed.). Chicago: Aldine-Atherton, 1972, pp. 136-179.

Waring, G.H. Horse Behavior: The Behavioral Traits and Adaptation of Domestic and Wild Horses, Including Ponies. Parkridge, NJ: Noyes, 1983.

WHO. Contemporary patterns of breast-feeding: Report on the WHO collaborative study on breast-feeding. Geneva: WHO, 1981.

- The prevalence and duration of breast-feeding. A critical review of the available information. World Health Statistics Quarterly 35(2), 1982. 
Wiggins, N., and Wiggins, J.S. A typological analysis of male preferences for female body types. Multivariate Behavioral Research 89-102, Jan. 1969.

Wiggins, J.S., Wiggins, N., and Conger, J.C. Correlates of heterosexual somatic preference. Journal of Personality and Social Psychology 10: 82-90, 1968.

Williams, G.C. Adaptation and Natural Selection. Princeton, NJ: Princeton University Press, 1966a.

- Natural selection, the costs of reproduction, and a refinement of Lack's principle. American Naturalist 100: 687-690, $1966 \mathrm{~b}$.

Wolff, G., and Steggerda, M. Female-male index of body build in negroes and whites: An interpretation of anatomical sex differences. Human Biology 15: 127-152, 1943. 